\title{
Myocardial Protection during Cardiac Surgery: Warm Blood versus Crystalloid Cardioplegia
}

\author{
Helene De Bruyn ${ }^{1}$, France Gelders ${ }^{*}$, Tine Gregoir ${ }^{2}$, Valerie Waelbers ${ }^{2}$, Pascal Starinieri², \\ Jean-Louis Pauwels², Jeroen Lehaen², Boris Robic ${ }^{1,2}$, Alaaddin Yilmaz², Urbain Mees², \\ Marc Hendrikx ${ }^{1,2 \#}$ \\ ${ }^{1}$ Faculty of Medicine and Life Sciences, Hasselt University, Hasselt, Belgium \\ ${ }^{2}$ Department of Cardiothoracic Surgery, Jessa Hospital, Hasselt, Belgium \\ Email: ${ }^{\#}$ marc.hendrikx@jessazh.be
}

Received 1 July 2014; revised 2 August 2014; accepted 13 August 2014

Copyright (C) 2014 by authors and Scientific Research Publishing Inc.

This work is licensed under the Creative Commons Attribution International License (CC BY).

http://creativecommons.org/licenses/by/4.0/

(c) $\underset{\mathrm{EY}}{\mathrm{EY}}$ Open Access

\section{Abstract}

Purpose: Prevention of myocardial injury is essential during cardiac surgery. Both crystalloid and blood cardioplegia are popular methods for myocardial protection. Most experimental studies have been in favor of blood cardioplegia. The objective of this study is to determine whether the use of warm blood cardioplegia (BCP) is superior to crystalloid cardioplegia (CCP) by means of myocardial injury markers and clinical outcome parameters. Materials and Methods: In a consecutive series of 293 patients, the first 150 received crystalloid cardioplegia, whereas the next 143 patients received blood cardioplegia. Postoperative myocardial injury was assessed by CTnI and CK-MB. Perioperative morbidity and mortality and clinical outcome parameters (need for inotropic support, ICU and hospital stay) were recorded. An unpaired student $t$-test was performed to analyse continuous postoperative variables relating to myocardial damage. The presence of possible confounders influencing the CTnI or CK-MB concentrations was tested using a student $t$-test for continuous variables, for categorical variables ANOVA was used. A final longitudinal model was created for CTnI and CK-MB. CTnI was analyzed by a mixed model with random intercept and slope. For all tests performed, statistical significance was $\mathbf{5 \%}$. Results: Both groups were well matched with respect to preoperative variables. No significant difference could be found in maximum postoperative levels of CTnI (8.8 $\pm 18.4 \mu \mathrm{g} / \mathrm{l}$ in BCP vs $9.6 \pm 16.5 \mu \mathrm{g} / \mathrm{l}$ in CCP, $\mathrm{p}=0.6455)$ or CK-MB $(19.2 \pm 31.0 \mu \mathrm{g} / \mathrm{l}$ in BCP vs $26.4 \pm 41.5 \mu \mathrm{g} / \mathrm{l}$ in CCP, $\mathrm{p}=0.1209)$. Nor was there any significant difference in other postoperative variables. Testing treatment effect over time proved only significant influence of the surgical intervention type on CTnI levels in time $(p<0.001)$. Conclusion: This study could not show significantly higher myocardial injury in the group of patients re-

\footnotetext{
*These authors contributed equally to the paper.

"Corresponding author.
} 
ceiving crystalloid cardioplegia versus warm blood cardioplegia. This suggests that warm blood cardioplegia does not confer superior myocardial protection. Surgical intervention type has an important effect on CTnI concentration in time, while the type of cardioplegia does not.

\section{Keywords}

Myocardium, Protection, Ischemia/Reperfusion, Myocardial Infarction, Cardiac Surgery

\section{Introduction}

Adequate protection of the myocardium is essential for successful clinical outcome during cardiac surgery. Despite the large number of experimental and clinical studies already conducted, the best strategy for myocardial protection is still not established [1].

Various strategies and combinations of techniques have been used over the years, but two main techniques have been supported most: the use of blood cardioplegia (BCP) and a crystalloid based solution. Initially, crystalloid cardioplegia (CCP) was introduced as an agent to allow for hypothermic hyperkalemic arrest. A large controversy persists between the use of blood and crystalloid cardioplegia (CCP) in terms of the benefits conferred to the heart by each [2]. Antegrade cold CCP is the simplest method of myocardial protection to implement. The quiet bloodless field and flaccid heart provide optimal conditions for the cardiac surgeon. Cardioplegic crystalloid solutions preserve ventricular function, prevent depletion of high-energy substrates, and maintain ultrastructural integrity. The advantages for BCP include oxygen delivery, the buffering capacity of blood, capillary flow distribution where red cells are essential, prevention of free radical generation, maintenance of oncotic pressure and restriction of hemodilution.

When investigating the release of cardiac enzymes, metabolic response and other laboratory tests, most experimental studies have been in favor of the use of blood cardioplegia. Blood cardioplegia could provide better protection because it more closely resembles normal physiology [3]. The oxygen carrying capacity of blood is of great importance, as oxygen is a substrate for ATP-production. Furthermore, using blood cardioplegia, the production of lactate during ischemia is delayed [4]. Blood cardioplegia causes less hemodilution [3] and is also proven to be superior in inhibiting proteins responsible for ischemia-reperfusion-induced apoptosis [5]. Nonetheless some studies state that cold blood cardioplegia does not offer better myocardial protection than a cold crystalloid solution does [6]. Blood cardioplegia can also impair visualization and crystalloid cardioplegia is therefore still used by some surgeons, particularly in port-access and robotic surgery [3].

The objective of this study is to determine whether warm blood cardioplegia is indeed better than crystalloid cardioplegia studied on the basis of myocardial damage after heart surgery using these two different cardioplegic solutions.

\section{Methods}

\subsection{Patient Selection}

We performed a retrospective review of a prospectively collected database from the department of Cardiothoracic Surgery at Jessa Hospital containing all adult cardiac procedures with cardiopulmonary bypass performed by three staff surgeons (U.M., A.Y. and M.H.) from October $15^{\text {th }}$, 2012 until July $29^{\text {th }}$, 2013. The database records detailed patient demographics, pre-operative risk factors, operative technique, post-operative hospital course and clinical outcome using 30-day in-hospital morbidity and mortality. This follow-up information was obtained using patient files, telephone contact with the patient or relatives or through the medical practitioner.

Two different methods of cardioplegia were used in 293 patients (208 men and 85 women), who were divided in two groups. The first 150 patients were assigned to receive crystalloid cardioplegia whereas the next 143 patients were assigned to receive blood cardioplegia. All three surgeons used both cardioplegic techniques.

\subsection{Operative Procedure}

All interventions were performed at moderate hypothermia $\left(32^{\circ} \mathrm{C}\right)$ with cardiopulmonary bypass and cannula- 
tion via the ascending aorta and 2-stage venous or bicaval cannulation. The left ventricle was vented either by aortic root venting or by a catheter that was introduced through the right superior pulmonary vein.

The administration of cardioplegia was pressure controlled in both groups, in which the cardioplegic solutions were infused into the root at a line-pressure of 150 - $180 \mathrm{mmHg}$. An aortic root cathether was inserted and attached to the cardioplegia line after deairing and aortic root pressure was continuously monitored through a pressure line attached to a strain gauge, as previously described [7].

The composition of the crystalloid cardioplegia solution is shown in Table 1. The route of delivery of both solutions was exclusively antegrade. The crystalloid cardioplegia was infused into the aortic root at $7^{\circ} \mathrm{C}$ at a flow rate of 250 - $300 \mathrm{~mL} / \mathrm{min}$ per square meter. To obtain cardiac arrest, an average of $750 \mathrm{~mL}$ of cardioplegic solution was injected immediately after cross-clamping. An additional dose of $300 \mathrm{~mL}$ crystalloid cardioplegia was injected each 15 minutes. The blood cardioplegic solution, as described by Calafiore, was made by adding oxygenated blood from the pump to a modified additive composition of $60 \mathrm{~mL}$, made of $40 \mathrm{~mL}$ Potassiumchloride (80 MEq), $5 \mathrm{~mL}$ Magnesiumchloride (1.5 g) and 15mL Bicarbonate (8.4\%) [8]. The blood cardioplegia was injected into the aortic root at a temperature of $32^{\circ} \mathrm{C}$ at a flow rate scheme described in Table 2.

\subsection{Dataset Preparation}

In order to obtain statistically valuable measurements, the dataset was slightly modified. The "ejection fraction" data which were proposed as $>50 \%$, "normal" or "preserved" were assumed to be $65 \%$, while the data proposed as "decreased" were assumed to be $40 \%$ and those proposed as "markedly decreased" were assumed to be $30 \%$. Secondly, the intervention types were categorized into four different groups, based on duration and severity. These are listed in Table 3. Although group three consists both of more severe surgery (aortic dissection, Bentall surgery) and small surgery types (ASD and PFO closure), this does not influence the results because they only constitute a small part of the dataset. Third, the preoperative CTnI values proposed as $<3 \mu \mathrm{g} / \mathrm{l}$

Table 1. Crystalloid cardioplegic solution.

\begin{tabular}{cc}
\hline & Crystalloid cardioplegia \\
\hline Sodium $(\mathrm{mmol} / \mathrm{l})$ & 139 \\
Potassium $(\mathrm{mmol} / \mathrm{l})$ & 32 \\
Magnesium $(\mathrm{mmol} / \mathrm{l})$ & 14 \\
Calcium $(\mathrm{mmol} / \mathrm{l})$ & 2 \\
Chloride $(\mathrm{mmol} / \mathrm{l})$ & 153 \\
Bicarbonate $(\mathrm{mmol} / \mathrm{l})$ & 8 \\
Hematocrit $(\%)$ & 0 \\
\hline
\end{tabular}

Table 2. Cardioplegia infusion scheme.

\begin{tabular}{|cccccc}
\hline \multicolumn{2}{c}{ 1st Infusion } & \multicolumn{2}{c}{ 2nd Infusion (15' after 1st) } & \multicolumn{2}{c}{ 3rd Infusion (15' after Previous) } \\
\hline Blood (ml/min) & $\mathrm{K}+(\mathrm{ml} / \mathrm{h})$ & Blood (ml/min) & $\mathrm{K}+(\mathrm{ml} / \mathrm{h})$ & Blood (ml/min) & $\mathrm{K}+(\mathrm{ml} / \mathrm{h})$ \\
\hline 250 & 325 & 250 & 195 & 250 & 146 \\
225 & 292 & 225 & 175 & 225 & 169 \\
200 & 260 & 200 & 156 & 200 & 117 \\
175 & 227 & 175 & 136 & 175 & 87 \\
150 & 195 & 150 & 117 & 150 & 72 \\
125 & 162 & 125 & 97 & 125 & 102 \\
100
\end{tabular}


Table 3. Intervention classification.

\begin{tabular}{|c|c|}
\hline Group & Intervention type \\
\hline 1 & CABG (possibly with ECMO of MECC) \\
\hline 2 & $\begin{array}{l}\text { Mini-aortic valve replacement } \\
\text { Aortic valve replacement } \\
\text { Mitral valve replacement (possibly video-assisted (VATS), possibly revision) } \\
\text { Tricuspid valve replacement }\end{array}$ \\
\hline 3 & $\begin{array}{l}\text { PFO closure } \\
\text { ASD closure } \\
\text { Aortic dissection } \\
\text { Bentall-surgery }\end{array}$ \\
\hline & $\begin{array}{l}\text { CABG or Endo-ACAB (endoscopic atraumatic coronary artery bypass) combined with valve surgery (aortic artificial valve, } \\
\text { mitral valve replacement, mitral artificial valve, mitral artificial valve, tricuspid valve replacement) } \\
\text { CABG combined with valve surgery (aortic artificial valve) and ablation }\end{array}$ \\
\hline 4 & $\begin{array}{l}\text { Valve surgery (tricuspid valve replacement, mitral artificial valve, aortic artificial valve, mitral valve replacement) combined } \\
\text { with ablation or mini-MAZE } \\
\text { Combined valve surgery (mitral valve and tricuspid valve replacement) } \\
\text { Valve surgery combined with closure PFO }\end{array}$ \\
\hline
\end{tabular}

were considered to be negligible and were given the value of zero. In one case, admitted as an acute myocardial infarct, no preoperative CTnI-value was determined, so this value could not be used for analysis. Fourth, one value in the database category "CTnI concentration immediately postoperative" was measured twice, given as 1.14 - 11.9. The second value was assumed to be the correct measurement so this one was included in the study. Atrial fibrillation or other cardiac dysrhythmias (atrial flutter, chronic or known atrial fibrillation) were categorized as 1, whether absence of dysrhythmia was categorized as zero. The value of zero was also assigned to patients with no postoperative dysrhythmia when taking amiodarone. As far as postoperative medication intake was concerned, seven patients were excluded from this analysis. One of these patients died intraoperatively from an aortic dissection and six patients in the crystalloid cardioplegia group were supposed to be given inotropic support without making note in the database. All other missing values in the dataset concerning inotropic support were assigned the value zero. The last change we made to the dataset, was in one case where the left mammary artery was not suitable as graft during a CABG, so this value was assigned as zero (meaning that this LIMA was not used during the intervention).

\subsection{Statistical Analysis}

Our study investigates whether blood cardioplegia is better than crystalloid cardioplegia. This was assessed by myocardial injury markers, perioperative morbidity and mortality. In order to obtain a primary image about the data, a selection of exploratory analyses was conducted. Preoperative demographic and investigative data, postoperative variables (e.g., medication intake or length of ICU stay) and 30-day mortality were compared between the crystalloid and blood cardioplegia groups. SAS Enterprise Guide 5.1 was used to perform these statistical analyses. In an unmatched sample, we performed an unpaired t-test to analyze the continuous variables, which will be expressed by using the respective means and standard deviations (mean \pm SD) in this manuscript. Because our hypothesis states that there would be less release of cardiac CTnI and CK-MB in the blood cardioplegia group, the p-value needed to be divided by two when the mean difference appeared to be negative. When the mean difference appeared to be positive, the correct p-value could be calculated via the formula one minus the t-test p-value divided by two $(1-\mathrm{p} / 2)$. Categorical variables (e.g. atrial fibrillation or mortality) were analyzed via a table analysis using the Chi-squared test.

Secondly, the presence of possible confounders was investigated, which could exert an influence on the maximal CTnI or CK-MB concentration. For categorical variables, the Chi-squared test was used to control whether these were equally divided within both cardioplegia groups. For continuous variables, both groups were compared based on the mean difference, standard variance, minimum and maximum values. Confounding was investigated using a student t-test for continuous variables, for categorical variables ANOVA (via procedure GLM) was employed.

The final goal was to create a model that included multiple observations through time per individual. Note 
that only the maximal troponin or CK-MB values were analyzed in previous analyses, while in fact multiple observations per person collected. To take this longitudinal structure into account, specialized models were fitted. Due to the fact that these models are based on maximum likelihood theory, malconvergence, which can be induced by overparameterization, is an important issue that should be dealt with. Therefore, a selection of explanatory variables - all variables that were shown to be possible confounders in the previous test (p-value $<0.25)$ - was used as covariates in a full model. The idea then was to use backward selection techniques to find a final model. Note that, for CK-MB and CTnI, different models were used to take the hierarchy in the data into account. CK-MB concentration, with only two measurements in time, was analyzed employing a pairwise ANOVA t-test for both groups, and a two-way ANOVA t-test for the calculated difference in CK-MB concentration between both groups. CTnI concentration, with three measurements in time, was analyzed via a "true" model for longitudinal data, more specific a mixed model with random intercept and slope (both statistically tested and proven to be significant with a p-value $<0.05$ ), in which we did not specify a type of random effects structure beforehand (denoted as "unstructured correlation"). In this way, we could test for the significance of treatment effect over time. This final analysis was performed by SAS 9.3.

Unless otherwise indicated, $\mathrm{p}$-values of $<0.05$ were considered statistically significant.

\section{Results}

\subsection{Patient Profile}

No patients were excluded from whole statistical analysis. Nevertheless some values were not appropriate for specific statistical tests, as indicated in "dataset preparation". The analysis included 143 patients in the blood cardioplegia group and 150 patients in the crystalloid group. Both groups were well matched: patient characteristics are shown in Table 4. The majority were CABG (90 in the blood cardioplegia—99 in the crystalloid cardioplegia group) or valve procedures (29 in the blood versus 32 in the crystalloid cardioplegia group). Valve procedures included port-access mitral procedures and minimal access isolated aortic valve replacements. Twentythree patients in the blood cardioplegia and 15 in the crystalloid group underwent combined procedures. One patient in the blood cardioplegia group underwent ASD closure, in the crystalloid group there were two Bentall procedures, 1 resection of atrial myxoma and 1 repair of a dissection of the ascending aorta. Those were categorized as "other".

In this cohort, 109 patients in the crystalloid and 105 patients in the blood cardioplegia group needed revascularization, either as a stand-alone procedure or in combination. In those patients, anatomical distribution of coronary lesions was comparable; a main stem lesion was present in 35 BCP and 36 CCP patients. At least one arterial graft was performed in 94 CCP and 103 BCP patients. Reasons for not using arterial grafting were dysfunctional graft due to subclavian artery stenosis/occlusion, use of both ITA's in previous surgery or combination of advanced age, diabetes and COPD. Twenty patients in both groups had bilateral ITA grafting.

Ninety-six patients were hypertensive in the crystalloid cardioplegia group, 90 patients in the blood cardioplegia group. Diabetes mellitus was present in 29 patients receiving crystalloid cardioplegia, and in 39 patients receiving blood cardioplegia. Preoperative ejection fraction was equivalent in both groups $(57 \% \pm 14 \%$ in the BCP group vs 55\% $\pm 13 \%$ in the CCP group). Five patients in the blood cardioplegia and 7 patients in the crystalloid cardioplegia group had long standing or persistent atrial fibrillation.

The mean cross-clamp time in the blood cardioplegia group was $52.9 \pm 25.3 \mathrm{~min}$ and in the crystalloid cardioplegia group $49.0 \pm 24.7 \mathrm{~min}$.

\subsection{Comparison of CTnI and CK-MB Release}

CTnI and CK-MB values obtained in both groups are shown in Table 5. CTnI was measured preoperatively, immediately postoperatively and between 9 and 15 hours after surgery. The maximum CTnI value was also determined. None of these measurements showed a significant difference between the two treatment groups.

CK-MB values were measured postoperatively and the maximal CK-MB value was determined. Neither of these two values was significantly different between the two treatment groups.

\subsection{Clinical Outcomes}

Intubation time was not significantly different in the BCP group $(21.3 \pm 32.7 \mathrm{~h})$ when compared to the CCP 
Table 4. Patient profile.

\begin{tabular}{|c|c|c|}
\hline Variable & Crystalloid cardioplegia & Blood cardioplegia \\
\hline Gender (M/F) & $105 / 45$ & $103 / 40$ \\
\hline Mean age & $71.1 \pm 9.8$ & $69.2 \pm 9.5$ \\
\hline \multicolumn{3}{|l|}{ Intervention type } \\
\hline CABG & 99 & 90 \\
\hline Valve surgery & 32 & 29 \\
\hline Combined CABG + valve \pm other & 15 & 23 \\
\hline Other & 4 & 1 \\
\hline \multicolumn{3}{|l|}{ Cardiovascular risk factors } \\
\hline Hypertension & 96 & 90 \\
\hline Diabetes mellitus & 29 & 39 \\
\hline AFib & 7 & 5 \\
\hline Ejection fraction & $55 \% \pm 13 \%$ & $57 \% \pm 14 \%$ \\
\hline Revascularization procedures & 109 & 105 \\
\hline \multicolumn{3}{|l|}{ Anatomic distribution of coronary lesions } \\
\hline Main stem & 36 & 35 \\
\hline LAD & 102 & 101 \\
\hline $\mathrm{CX}$ & 79 & 84 \\
\hline RAC & 87 & 85 \\
\hline LITA & 94 & 98 \\
\hline RITA (no LITA) & 0 & 5 \\
\hline BITA & 20 & 20 \\
\hline VSM & 80 & 78 \\
\hline Cross-clamp time (min) & $49.0 \pm 24.7$ & $52.9 \pm 25.3$ \\
\hline Perfusion time (min) & $92.8 \pm 38.5$ & $91.4 \pm 40.2$ \\
\hline
\end{tabular}

$\mathrm{LAD}=$ left anterior descending artery; $\mathrm{CX}=$ left circumflex artery; RAC = right coronary artery; LITA = left internal thoracic artery; RIMA = right internal thoracic artery; BITA = bilateral internal thoracic artery; VSM = vena saphena magna.

Table 5. Analysis of myocardial damage markers.

\begin{tabular}{|c|c|c|c|c|c|}
\hline Variable & СCP & $\mathrm{BCP}$ & t-Value & p-Value & Outcome \\
\hline Preop CTnI $(\mu \mathrm{g} / \mathrm{l})$ & $9.7 \pm 19.9$ & $6.4 \pm 18.1$ & -1.03 & 0.1522 & n.s. \\
\hline Immediate postop CTnI $(\mu \mathrm{g} / \mathrm{l})$ & $6.9 \pm 14.6$ & $4.2 \pm 6.7$ & 0.84 & 0.8 & n.s. \\
\hline CTnI 9 - 15 h $(\mu \mathrm{g} / \mathrm{l})$ & $7.1 \pm 10.9$ & $6.6 \pm 8.6$ & 0.92 & 0.8194 & n.s. \\
\hline Max postop CTnI ( $\mu \mathrm{g} / \mathrm{l})$ & $9.6 \pm 16.5$ & $8.8 \pm 18.4$ & -0.37 & 0.6455 & n.s. \\
\hline Immediate postop CK-MB ( $\mu \mathrm{g} / \mathrm{l})$ & $22.8 \pm 37.3$ & $14.4 \pm 28.8$ & -1.510 & 0.0667 & n.s. \\
\hline Max postop CK-MB $(\mu \mathrm{g} / \mathrm{l})$ & $26.4 \pm 41.5$ & $19.2 \pm 31.0$ & -1.180 & 0.1209 & n.s. \\
\hline Immediate postop CK ( $\mu \mathrm{g} / \mathrm{l})$ & $268.2 \pm 242.7$ & $272.1 \pm 751.0$ & 0.050 & 0.5187 & n.s. \\
\hline Max postop CK $(\mu \mathrm{g} / \mathrm{l})$ & $637.9 \pm 444.0$ & $807.2 \pm 1277.4$ & 1.180 & 0.8792 & n.s. \\
\hline
\end{tabular}

Values are expressed as mean \pm SD. CCP = crystalloid cardioplegia; $\mathrm{BCP}=$ blood cardioplegia. 
group $(18.7 \pm 39.3 \mathrm{~h}, \mathrm{p}=0.724)$. The intensive care unit stay was $98.0 \pm 85.6 \mathrm{~h}$ in the crystalloid cardioplegia group and $108.7 \pm 111.4 \mathrm{~h}$ in the blood cardioplegia group (Table 6). Thirty-four patients in the BCP group and forty-one in the CCP group did not receive any inotropic support (levosimendan, milrinon or dobutamine). Vasoconstrictive support with noradrenaline was needed in 123 patients in the crystalloid group and 111 patients in the blood group. Three patients were given levosimendan $(0.2 \mu \mathrm{g} / \mathrm{kg} / \mathrm{min})$ in the BCP group, 2 patients received the same dose in the CCP group. A low dose of dobutamine $(<6 \mu \mathrm{g} / \mathrm{kg} / \mathrm{min})$ was given to 82 patients in the BCP group and 89 patients in the CCP group. Higher doses were required in 3 patients in the BCP group (6.1 $\mathrm{kg} / \mathrm{\mu g} / \mathrm{min}$ in 1 patient, $12.3 \mu \mathrm{g} / \mathrm{kg} / \mathrm{min}$ in 1 patient and $13.1 \mu \mathrm{g} / \mathrm{kg} / \mathrm{min}$ in 1 patient) and 6 patients in the CCP group $(6.1 \mu \mathrm{g} / \mathrm{kg} / \mathrm{min}$ in 2 patients, $7.0 \mu \mathrm{g} / \mathrm{kg} / \mathrm{min}$ in 1 patient, $8.0 \mu \mathrm{g} / \mathrm{kg} / \mathrm{min}$ in 1 patient, $10.0 \mu \mathrm{g} / \mathrm{kg} / \mathrm{min}$ in 1 patient, $11.0 \mu \mathrm{g} / \mathrm{kg} / \mathrm{min}$ in 1 patient). A low dose of milrinon $(<1 \mu \mathrm{g} / \mathrm{kg} / \mathrm{min})$ was given mainly for right ventricular support to 56 patients in the BCP group, and to 41 patients in the CCP group. No patient required high dose milrinon treatment.

Acquired atrial fibrillation during hospital stay occurred in 54 patients (43.17\%) in the BCP group and 47 patients (37.06\%) in the CCP group ( $\mathrm{p}=0.296$, n.s.).

Seven patients died in the CCP group (4.67\%) of which one died intraoperatively as result of an aortic dissection. In the BCP group, 5 patients died (3.52\%) (Table 6). This difference in mortality rate was not significant $(\mathrm{p}=$ $0.662)$.

Peak CTnI release was significantly different between patients requiring inotropic agents $(10.2 \pm 19.2 \mu \mathrm{g} / \mathrm{L})$ and patients who did not $(5.8 \pm 8.8 \mu \mathrm{g} / \mathrm{L}, \mathrm{p}=0.005)$. This implicates a correlation between myocardial damage and inotropic support.

\subsection{Incremental Risk Factors for CTnI and CK-MB Release}

This study investigates not only the effect of cardioplegia on CTnI and CK-MB release, but also the presence of possible confounding variables which influence the postoperative myocardial injury markers. These variables were operative procedure type, preoperative CTnI concentration, age, diabetes mellitus, hypertension, ejection fraction, cross-clamp time, left main stem lesion and sex. All parameters were equally distributed in both groups. This implies that, even when the parameter was statistically considered as a confounder, this influence on CTnI or CK-MB could not explain the difference in CTnI or CK-MB release between both cardioplegia groups. The final reduced mixed model for CTnI contained the following explanatory variables: cardioplegia and intervention type. The final reduced mixed model for CK-MB contained cardioplegia, sex and intervention type as explanatory variables.

The type of intervention, classified in four groups, might influence CTnI release because of the fact that more prolonged and complex interventions might do more damage to the heart, independent of the influence of the cardioplegia type on CTnI and CK-MB release. Statistical analysis proved a significant influence on both myocardial injury markers with a p-value of 0.011 for CTnI and 0.001 for CK-MB. Age, diabetes mellitus, main

Table 6. Postoperative outcome data.

\begin{tabular}{|c|c|c|c|c|c|}
\hline Variable & CCP & $\mathrm{BCP}$ & t-Value & p-Value & Outcome \\
\hline Intubation time (h) & $18.7 \pm 39.23$ & $21.3 \pm 32.7$ & 0.60 & 0.724 & n.s. \\
\hline Intensive care stay (h) & $98.0 \pm 85.6$ & $108.7 \pm 111.4$ & 0.91 & 0.819 & n.s. \\
\hline Inotropic support & $109 / 150(72.6 \%)$ & 109/143 (76.2\%) & 0.01 & 0.915 & n.s. \\
\hline Noradrenalin $(\mu \mathrm{g} / \mathrm{kg} / \mathrm{min})$ & $0.08 \pm 0.09$ & $0.08 \pm 0.09$ & -0.15 & 0.442 & n.s. \\
\hline Dobutamin $(\mu \mathrm{g} / \mathrm{kg} / \mathrm{min})$ & $2.03 \pm 2.00$ & $1.74 \pm 2.08$ & -1.24 & 0.109 & n.s. \\
\hline Milrinon ( $\mu \mathrm{g} / \mathrm{kg} / \mathrm{min})$ & $0.06 \pm 0.10$ & $0.10 \pm 0.15$ & 2.76 & 0.997 & n.s. \\
\hline Isosorbide dinitrate $(\mathrm{mL} / \mathrm{h})$ & $0.69 \pm 0.86$ & $0.59 \pm 0.81$ & -1.04 & 0.149 & n.s. \\
\hline Levosimendan ( $\mu \mathrm{g} / \mathrm{kg} / \mathrm{min})$ & $0.0028 \pm 0.024$ & $0.0042 \pm 0.0289$ & 0.46 & 0.676 & n.s. \\
\hline Atrial fibrillation/Atrial flutter & 53/143 (37.06\%) & 60/139 (43.17\%) & 1.0931 & 0.295 & n.s. \\
\hline 30 days mortality & $7 / 150(4.67 \%)$ & $5 / 142(3.52 \%)$ & 0.2429 & 0.6621 & n.s. \\
\hline
\end{tabular}


stem lesion, sex and hypertension showed no significant influence on both cardiac injury markers, with a pvalue $>0.05$. The preoperative ejection fraction was proven to exert an important influence $(p=0.004)$ on CTnI concentration, without significant increment of CK-MB ( $\mathrm{p}=0.791)$. Cross-clamp time as a confounder could, if so, be explained on the basis of longer cross-clamp time causing more damage to the heart because longer interruption of blood flow to the heart. Although we could not find a significant association between cross-clamp time and CTnI release (p-value 0.584), there is a significant influence of this parameter on CK-MB release $(\mathrm{p}=$ 0.036). Preoperative maximal CTnI concentration was significantly proven to increment CTnI concentration ( $p$ $<0.001$ ). Analysis of the influence of this parameter only in the group of patients without preoperative elevated CTnI concentration proved that this statement still seemed to be true $(\mathrm{p}<0.001)$. An influence on CK-MB concentration could also be established. Statistical models (Table 7) were established with these variables investigating their influence on CK-MB and CTnI. Testing the treatment effect over time by comparing the two methods of cardioplegia proved only significant influence of the intervention type on CTnI concentration in time (p $<0.001$ ). The type of cardioplegic solution did not influence this CTnI concentration in time significantly. These results are summarized in Table 8.

Table 7. Statistical modelling.

\begin{tabular}{|c|c|c|}
\hline Myocardial injury marker & Full Model & Reduced Model \\
\hline $\begin{array}{c}\text { Max postoperative } \\
\text { CTnI concentration }(\mu \mathrm{g} / \mathrm{l})\end{array}$ & $\begin{array}{l}\mathrm{Y}_{\mathrm{ijmn}}=\mathrm{C}_{\mathrm{i}}+\mathrm{DM}_{\mathrm{j}}+\beta \mathrm{E}+\mathrm{I}_{\mathrm{m}}+\left(\mathrm{C}_{\mathrm{i}}^{*} \mathrm{DM}_{\mathrm{j}}\right)+\left(\mathrm{C}_{\mathrm{i}}^{*} \beta \mathrm{E}\right)+\left(\mathrm{C}_{\mathrm{i}}^{*} \mathrm{I}_{\mathrm{m}}\right) \\
\quad+\left(\mathrm{DM}_{\mathrm{i}} * \beta \mathrm{E}\right)+\left(\mathrm{DM}_{\mathrm{j}} \mathrm{I}_{\mathrm{m}}\right)+\left(\beta \mathrm{E}^{*} \mathrm{I}_{\mathrm{m}}\right) \\
\mathrm{i}=0,1 \\
\mathrm{j}=0,1 \\
\mathrm{~m}=1,2,3,4 \\
\mathrm{n}=1, \cdots, \mathrm{n}_{\mathrm{ijm}}\end{array}$ & $\begin{array}{l}\mathrm{Y}_{\mathrm{imn}}=\mathrm{C}_{\mathrm{i}}+\mathrm{I}_{\mathrm{m}} \\
\mathrm{i}=0,1 \\
\mathrm{~m}=1,2,3,4 \\
\mathrm{n}=1, \cdots, \mathrm{n}_{\mathrm{im}}\end{array}$ \\
\hline $\begin{array}{l}\text { Max postoperative CK-MB } \\
\text { concentration }(\mu \mathrm{g} / \mathrm{l})\end{array}$ & $\begin{aligned} & \mathrm{Y}_{\mathrm{jlmn}}= \gamma \cdot \mathrm{L}+\mathrm{Cj}+\beta \cdot \mathrm{K}+\mathrm{Gl}+\mathrm{Im}+(\gamma \cdot \mathrm{L} * \mathrm{Cj})+\left(\gamma \cdot \mathrm{I}^{*} \beta \cdot \mathrm{K}\right) \\
&+(\gamma \cdot \mathrm{L} * \mathrm{Gl})+(\gamma \cdot \mathrm{L} * \mathrm{Im})+(\mathrm{Cj} \beta \cdot \mathrm{K})+\left(\mathrm{C}^{*} \mathrm{G}\right) \mathrm{jl} \\
&+\left(\mathrm{C}^{*} \mathrm{I}\right) \mathrm{jm}+\left(\beta \cdot \mathrm{K}^{*} \mathrm{Gl}\right)+\left(\beta \cdot \mathrm{K}^{*} \mathrm{Im}\right)+\left(\mathrm{G}^{*} \mathrm{I}\right) \mathrm{lm} \\
& \mathrm{j}=0,1 \\
& \mathrm{l}=0,1 \\
& \mathrm{~m}=1,2,3,4 \\
& \mathrm{n}=1, \cdots, \mathrm{n}_{\mathrm{jlm}}\end{aligned}$ & $\begin{array}{l}Y_{j l m n}=C j+G l+I m+\left(C^{*} I\right) j m+\left(G^{*} l\right) l m \\
j=0,1 \\
l=0,1 \\
m=1,2,3,4 \\
n=1, \cdots, n_{j l m}\end{array}$ \\
\hline
\end{tabular}

This figure shows both statistical models containing only variables influencing the max postoperative CTnI concentration ( $\mu \mathrm{g} / \mathrm{l})$ resp. the max postoperative CK-MB concentration $(\mu \mathrm{g} / \mathrm{l})$ on significance level 0.05 . Y = max postoperative CTnI resp. CK-MB concentration $(\mu \mathrm{g} / \mathrm{l})$; $\mathrm{C}=$ cardioplegia type; DM = diabetes mellitus; $\mathrm{E}$ = ejection fraction; $\mathrm{I}$ = intervention type; $\mathrm{L}$ = age (years); $\mathrm{K}=$ cross-clamp time (h); $\mathrm{G}=$ sex.

Table 8. Analysis of preoperative variables.

\begin{tabular}{|c|c|c|c|}
\hline & Statistical analysis & $\begin{array}{c}\text { Confounder max } \\
\text { postoperative CTnI } \\
\text { concentration }\end{array}$ & $\begin{array}{c}\text { Confounder max } \\
\text { postoperative CK-MB } \\
\text { concentration }\end{array}$ \\
\hline Operative procedure type & ANOVA (proc GLM) & yes, $\mathrm{p}$-value $=0.0107$ & yes, p-value 0.0008 \\
\hline $\begin{array}{c}\text { Preoperative max CTnI concentration ( } \mu \mathrm{g} / \mathrm{l}) \text { : } \\
\text { only normal values (total: } 255)\end{array}$ & ANOVA (proc GLM) & yes, p-value $<0.001$ & yes, p-value 0.0034 \\
\hline Preoperative max CTnI concentration ( $\mu \mathrm{g} / \mathrm{l})$ : total & ANOVA (proc GLM) & yes, p-value $<0.001$ & no, p-value 0.1162 \\
\hline Age & ANOVA (proc GLM) & no, p-value 0.7557 & no, p-value 0.2179 \\
\hline Diabetes mellitus & t-test & no, p-value 0.1076 & no, p-value 0.3752 \\
\hline Hypertension & t-test & no, p-value 0.5991 & no, p-value 0.5770 \\
\hline Ejection fraction & ANOVA (proc GLM) & yes, p-value 0.0036 & no, p-value 0.7908 \\
\hline Cross-clamp time & ANOVA (proc GLM) & no, p-value 0.5840 & yes, p-value 0.0362 \\
\hline Main stem (LCA) & t-test & no, p-value 0.3242 & no, p-value 0.4171 \\
\hline Sex & t-test & no, p-value 0.7235 & no, p-value 0.2001 \\
\hline
\end{tabular}




\section{Discussion}

A recent meta-analysis [9] reviewing 12 RCTs, showed that there was no significant difference in the risk of mortality, acquired atrial fibrillation or stroke in cold blood versus crystalloid cardioplegia. The only significant difference was a lower incidence of perioperative myocardial infarction in the blood cardioplegia group. The authors concluded that both crystalloid and cold blood cardioplegia are safe and effective for myocardial protection.

However, the question whether this can be extrapolated to warm blood cardioplegia $\left(32^{\circ} \mathrm{C}\right)$ remains unresolved. Potential advantages of this technique, as described by Calafiore et al. are minimal dilution of the patient and economic considerations as the method is simple and does not require expensive equipment such as heat exchangers [8].

Therefore, we compared a consecutive series of 150 patients operated on by crystalloid cardioplegia with 143 patients using warm blood cardioplegia. We decided to use cardiac troponin I as a marker for myocardial damage due to its specificity and the fact that it is far more reliable than postoperative ECG changes that may be blurred by new onset conduction disturbances, not uncommon in the early postoperative period.

Our data show no significant difference in rise of CTnI at $12 \mathrm{~h}$ (interval $9-15 \mathrm{~h}$ ) post unclamping of the aorta: $6.6 \pm 8.6 \mu \mathrm{g} / \mathrm{L}$ in blood versus $7.1 \pm 10.9 \mu \mathrm{g} / \mathrm{L}$ in crystalloid cardioplegia $(\mathrm{p}=0.82)$, nor with respect to maximal values. This was confirmed by CK-MB values, that also were not significantly different between both groups.

The fact that we were unable to find a difference in myocardial protection between the two regimens, suggests that at least part of the superior protection by cold blood cardioplegia versus crystalloid as reported in metaanalyses, is lost by administering the cardioplegic solution at warm temperatures. However, our data indicate that even in this setting, both crystalloid and warm blood cardioplegia are safe techniques for myocardial protection.

Since we found equal myocardial protection in both groups, it could be expected that clinical outcome for the patients was comparable.

This was confirmed by the data: perioperative and in-hospital mortality was $3.5 \%$ in the blood cardioplegia group and $4.7 \%$ in the crystalloid cardioplegia $(\mathrm{p}=0.66)$. Need for inotropic support was similar in both groups: 109 patients in each group required inotropes (72.6\% in BCP versus $76.2 \%$ in CCP). The use of vasoconstrictive agents, phosphodiesterase inhibitors or direct calcium sensitizers was similar in crystalloid versus blood cardioplegia. This also resulted in comparable intubation times in both groups $(18.7 \pm 39.3 \mathrm{~h}$ in crystalloid vs $21.3 \pm$ $32.7 \mathrm{~h}$ in blood cardioplegia patients) and similar length of stay in ICU ( $98.0 \pm 85.6 \mathrm{~h}$ vs $108.7 \pm 111.4 \mathrm{~h})$. The incidence of atrial fibrillation showed no correlation with the type of cardiolegia used: $37.1 \%$ of patients in the CCP group and $43.2 \%$ in the BCP group developed transient atrial fibrillation.

Previous reports have suggested that blood cardioplegia would be particularly beneficial in high-risk patients [7]. Therefore, we looked at myocardial damage in patients with a main stem lesion. There was no significant difference between both groups in patients treated for main stem lesion: $6.6 \pm 8.8 \mu \mathrm{g} / \mathrm{L}$ in crystalloid $(\mathrm{n}=36)$ versus $7.3 \pm 9.6 \mu \mathrm{g} / \mathrm{L}$ in blood cardioplegia $(\mathrm{n}=33 ; \mathrm{p}=0.37$ ). Despite the exclusive antegrade route of administration, those values did not differ from the values of the global group.

When considering the "long” clamping times (>60 min X-clamp), higher average CTnI were observed. However no significant difference between both groups was present $(12.5 \pm 13.0 \mu \mathrm{g} / \mathrm{L}$ in crystalloid $(\mathrm{n}=34)$ versus $10.0 \pm 11.0 \mu \mathrm{g} / \mathrm{L}$ in blood cardioplegia $(\mathrm{n}=42, \mathrm{p}=0.18)$ ).

Despite numerous papers on myocardial protection during cardiac surgery, the number of studies directly comparing warm blood to cold crystalloid cardioplegia remains scarce. Dar was not able to show a convincing superiority of exclusive antegrade administration of blood cardioplegia over crystalloid cardioplegia (no significant difference in CTnT release, whereas marginal difference in CK-MB release) [5]. Jacquet et al. observed lower CTnI and CK-MB levels in a randomized trial in blood cardioplegia versus crystalloid, however the cross-clamp times were significantly longer in the crystalloid group, which makes interpretation of the data difficult [10].

In general, we would not advocate the use of warm blood cardioplegia over cold blood cardioplegia. Whereas most of the studies comparing cold blood with crystalloid cardioplegia report some benefit for the use of blood in terms of reduced perioperative myocardial infarction or markers of damage [1] [11], this benefit seems to be lost in our series using warm blood cardioplegia. This is already and correctly reflected in daily cardiac surgical 
practice. In the UK, a survey in 2004 found that 56\% of surgeons used cold blood cardioplegia, 14\% used warm blood cardioplegia, 14\% used crystalloid cardioplegia. Interesting, still 16\% did not use any cardioplegia, preferring intermittent cross-clamping [12].

\section{Acknowledgements}

We would like to thank Thomas Neyens and Kim Van Kerckhove, CENSTAT Department of Statistics at Uhasselt for their statistical advice.

\section{References}

[1] Giordano, P., Scrascia, G., D’Agostino, D., Mastro, F., Rotunno, C., Conte, M., Rociola, R. and Paparella, D. (2013) Myocardial Damage Following Cardiac Surgery: Comparison between Single-Dose Celsior Cardioplegic Solution and Cold Blood Multi-Dose Cardioplegia. Perfusion, 28, 496-502. http://dx.doi.org/10.1177/0267659113486827

[2] Ferreira, R., Fraga, C., Carrasquedo, F., Hourqueble, H., Grana, D. and Milei, J. (2003) Comparison between Warm Blood and Crystalloid Cardioplegia during Open Heart Surgery. International Journal of Cardiology, 90, 253-260. http://dx.doi.org/10.1016/S0167-5273(02)00559-4

[3] Guru, V., Omura, J., Alghamdi, A.A., Weisel, R. and Fremes, S.E. (2006) Is Blood Superior to Crystalloid Cardioplegia? A Meta-Analysis of Randomized Clinical Trials. Circulation, 114, i330-i338.

[4] Yamamoto, H., Magishi, K., Goh, K., Sasajima, T. and Yamamoto, F. (2009) Cardioprotective Effects of Normothermic Reperfusion with Oxygenated Potassium Cardioplegia: A Possible Mechanism. Interactive Cardiovascular and Thoracic Surgery, 9, 598-604. http://dx.doi.org/10.1510/icvts.2008.201277

[5] Dar, M.I. (2005) Cold Crystalloid versus Warm Blood Cardioplegia for Coronary Artery Bypass Surgery. Annals of Thoracic and Cardiovascular Surgery, 11,382-385.

[6] Sá, M.P., Rueda, F.G., Ferraz, P.E., Chalegre, S.T., Vasconcelos, F.P. and Lima, R.C. (2012) Is There Any Difference between Blood and Crystalloid Cardioplegia for Myocardial Protection during Cardiac Surgery? A Meta-Analysis of 5576 Patients from 36 Randomized Trials. Perfusion, 27, 535-546. http://dx.doi.org/10.1177/0267659112453754

[7] Hendrikx, M., Jiang, H., Gutermann, H., Toelsie, J., Renard, D., Briers, A., Pauwels, J.L. and Mees, U. (1999) Release of Cardiac Troponin I in Antegrade Crystalloid versus Cold Blood Cardioplegia. Journal of Thoracic and Cardiovascular Surgery, 118, 451-459. http://dx.doi.org/10.1016/S0022-5223(99)70182-0

[8] Calafiore, A.M., Teodori, G., Mezzetti, A., Bosco, G., Verna, A.M., Di Giammarco, G. and Lapenna, D. (1995) Intermittent Antegrade Warm Blood Cardioplegia. Annals of Thoracic Surgery, 59, 398-402. http://dx.doi.org/10.1016/0003-4975(94)00843-V

[9] Zeng, J., He, W., Qu, Z., Tang, Y., Zhou, Q. and Zhang, B. (2014) Cold Blood versus Crystalloid Cardioplegia for Myocardial Protection in Adult Cardiac Surgery: A Meta-Analysis of Randomized Controlled Studies. Journal of Cardiothoracic and Vascular Anesthesia, 28, 674-681. http://dx.doi.org/10.1053/j.jvca.2013.06.005

[10] Jacquet, L.M., Noirhomme, Ph., Van Dyck, M.J., El Khoury, G.A., Matta, A.J., Goenen, M.J. and Dion, R.A. (1999) Randomized Trial of Intermittent Antegrade Warm Blood versus Cold Crystalloid Cardioplegia. Annals of Thoracic Surgery, 67, 471-477. http://dx.doi.org/10.1016/S0003-4975(98)01198-9

[11] Braathen, B. and Tønnessen, T. (2010) Cold Blood Cardioplegia Reduces the Increase in Cardiac Enzyme Levels Compared with Cold Crystalloid Cardioplegia in Patients Undergoing Aortic Valve Replacement for Isolated Aortic Stenosis. Journal of Thoracic and Cardiovascular Surgery, 139, 874-880. http://dx.doi.org/10.1016/j.jtcvs.2009.05.036

[12] Karthik, S., Grayson, A.D., Oo, A.Y. and Fabri, B.M. (2004) A Survey of Current Myocardial Protection Practices during Coronary Artery Bypass Grafting. Annals of the Royal College of Surgeons of England, 86, 413-415.

http://dx.doi.org/10.1308/147870804669 
Scientific Research Publishing (SCIRP) is one of the largest Open Access journal publishers. It is currently publishing more than 200 open access, online, peer-reviewed journals covering a wide range of academic disciplines. SCIRP serves the worldwide academic communities and contributes to the progress and application of science with its publication.

Other selected journals from SCIRP are listed as below. Submit your manuscript to us via either submit@scirp.org or Online Submission Portal.
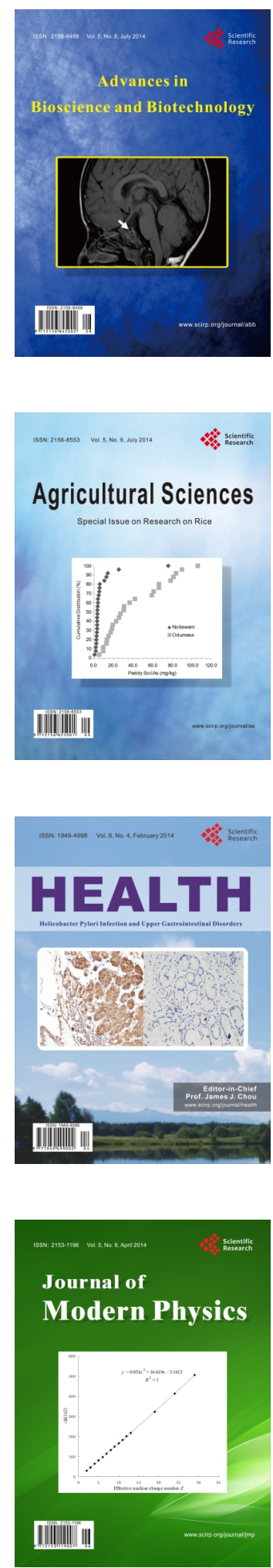
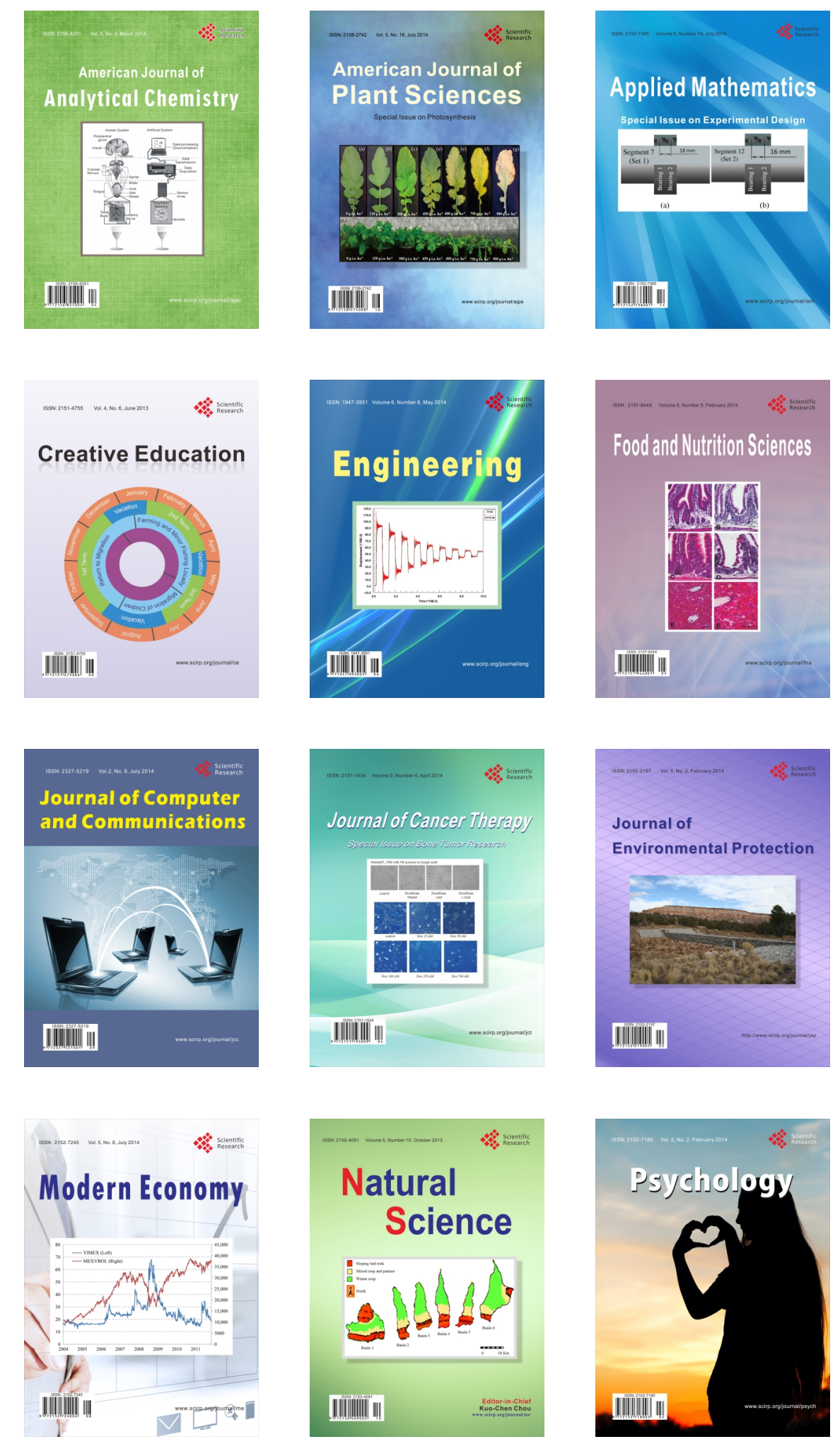